OPEN ACCESS

Edited by:

Michael S. Lee,

University of Minnesota Twin Cities,

United States

Reviewed by:

Zoe Rebecca Williams,

Medical Center, University of

Rochester, United States

Devin Dean Mackay,

Indiana University, Purdue University

Indianapolis, United States

*Correspondence:

Steven Roth

rothgas@uic.edu

Specialty section:

This article was submitted to

Neuro-Ophthalmology,

a section of the journal

Frontiers in Neurology

Received: 22 May 2018

Accepted: 21 June 2018

Published: 10 July 2018

Citation:

Roth S and Moss HE (2018) Update

on Perioperative Ischemic Optic

Neuropathy Associated With

Non-ophthalmic Surgery.

Front. Neurol. 9:557.

doi: 10.3389/fneur.2018.00557

\section{Update on Perioperative Ischemic Optic Neuropathy Associated With Non-ophthalmic Surgery}

\author{
Steven Roth ${ }^{1 *}$ and Heather E. Moss ${ }^{2}$ \\ ${ }^{1}$ Department of Anesthesiology, and Ophthalmology and Visual Sciences, University of Illinois at Chicago, Chicago, IL, \\ United States, ${ }^{2}$ Departments of Ophthalmology and Neurology \& Neurological Sciences, Stanford University, Palo Alto, CA, \\ United States
}

Perioperative visual loss (POVL) is a rare, serious complication of non-ophthalmic surgeries. Ischemic optic neuropathy (ION), and retinal arterial occlusion (RAO) are the main causes (1, 2). Less frequent are cortical blindness (3), acute glaucoma (4), and choroidal and vitreous hemorrhage (5). ION is the most common cause for which the neurologist or neuro-ophthalmologist is consulted as it is associated either with a normal ophthalmic exam (posterior ION, PION), or less often, with optic nerve (ON) head swelling (anterior ION, AION). The presumed cause is impaired blood supply to the optic nerve (Figure 1). The most common surgical procedures complicated by ION are cardiac surgery and spinal fusion. Retrospective studies, surveys, and case reports are the basis of most knowledge regarding peri-operative ION (polON), with cohort and case-control studies helping to identify candidate risk factors $(6,7)$. Animal models have provided insight regarding mechanisms (8). This mini-review is an update on the latest advancements regarding polON in non-ophthalmic surgeries in epidemiological, clinical, and animal studies.

\begin{abstract}
Keywords: cardiac surgery, ischemic optic neuropathy, spinal fusion, optic nerve, anterior ischemic optic neuropathy, posterior ischemic optic neuropathy
\end{abstract}

\section{EPIDEMIOLOGY}

Encouragingly, but for uncertain reasons, yearly rates of poION in spinal fusion have decreased, with an overall rate of $0.01 \%$ in 1998-2012 (7). Explanations may include greater utilization of minimally invasive spine surgery and surgical staging, and changes in anesthesia practice such as higher blood pressure levels and lower fluid administration $(7,9)$. Often not appreciated is that poION occurs with cardiac surgery at a rate of $0.06-0.113 \%$, 6 -fold greater vs. spinal fusion $(6,10,11)$. poION has also been reported after head and neck surgery $(12,13)$, joint replacement (14), nasal and sinus surgery (15), vascular and general surgery, radical prostatectomy, gynecologic surgery, and liposuction (16).

\section{CLINICAL PRESENTATION}

Symptoms are typically reported within 1-2 d after surgery and frequently upon awakening (17), although first report may be delayed in those sedated after surgery (18). Painless central or peripheral vision loss or both, are common, with color vision decreased or absent, and usually bilateral. Unilateral or asymmetric cases have a relative afferent pupillary defect. Ophthalmoscopic 


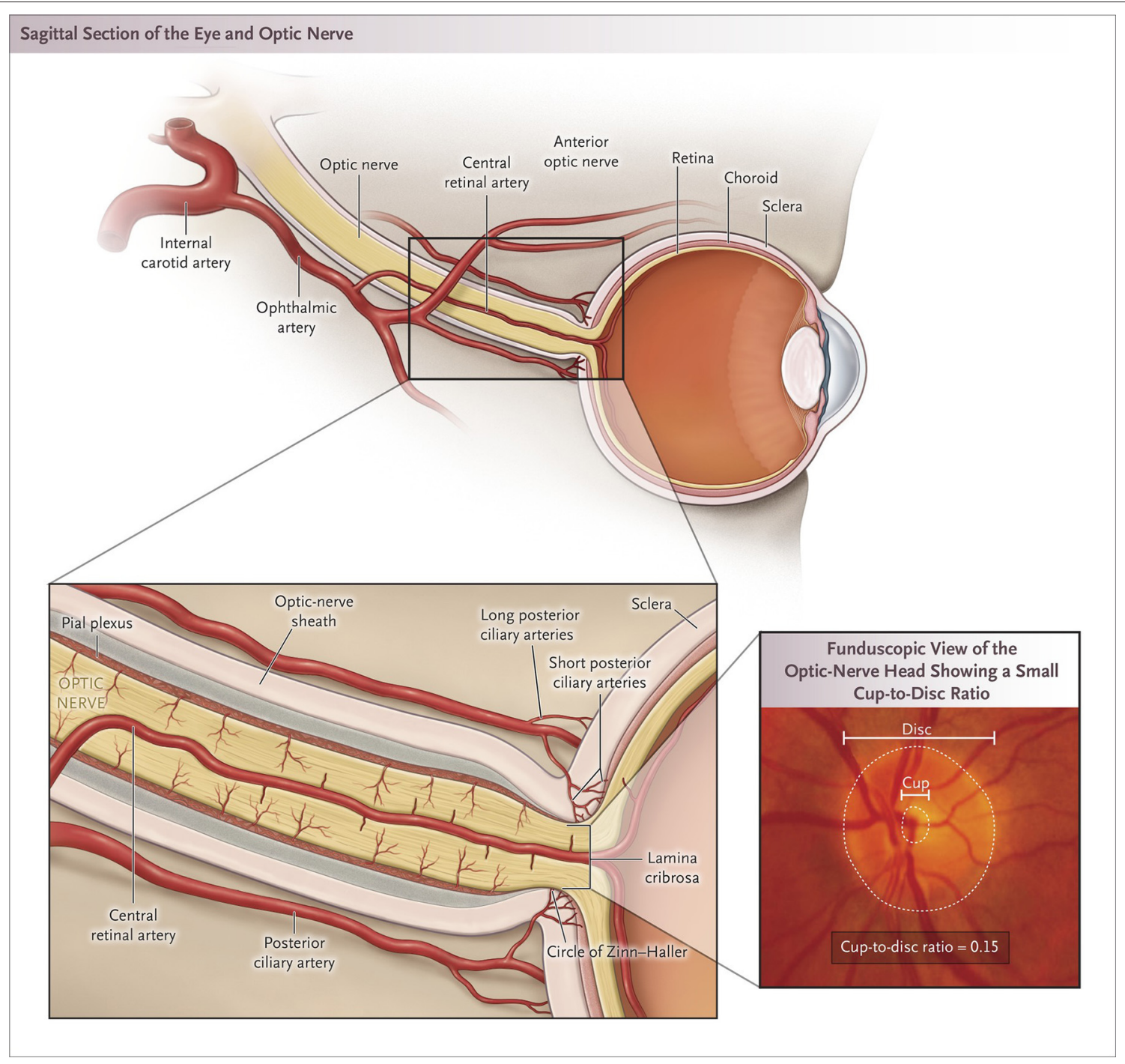

FIGURE 1 | Blood supply to the optic nerve and ON head structure. The blood supply is primarily from the ophthalmic artery. The posterior ON is supplied by pial branches of the ophthalmic artery posteriorly and the posterior ciliary arteries anteriorly; the supply to the central region is limited to the branches that penetrate deeply. The ON head is supplied by the circle of Zinn, from the short posterior ciliary arteries, and from choroidal vessels. The cup-to-disc ratio is the diameter of the central cup divided by diameter of the entire disc [Biousse and Newman (2) used with permission].

exam does not identify causes for the vision loss other than optic neuropathy. PoION can be AION, with, acutely, a swollen ON head, or PION, with a normal ON head in the acute state; most spinal fusion cases have been PION (16). Lingering anesthetic effects, or sedation, may render patient cooperation difficult for eye examination.

Buono and Foroozan's retrospective series of 83 cases provides insight into poPION's heterogeneity (16), with 54\% after spine surgery, $13 \%$ followed radical neck dissection, and $33 \%$ other surgery. Mean age was 52 years with $66 \%$ male. In $75 \%$, visual loss was noted within $24 \mathrm{~h}$. Over $60 \%$ were bilateral. Initial visual acuity was light perception in $54 \%$ of eyes.

MRI is generally obtained in patients with perioperative visual loss (POVL) to rule out intracranial pathology, and orbital MRI should be obtained to examine the ONs. Usually there are normal retro-bulbar ONs, although there are reports of ON enlargement from edema and perineural enhancement (19, 20). Diffusionweighted imaging may enhance diagnostic sensitivity (21). Visual evoked potentials (VEPs) are abnormal (22).

Over weeks to months, ON swelling resolves in AION and optic atrophy develops in AION and PION. In Buono and Foroozan's case series, vision improved in $38 \%$, but of 14 with no light perception, 12 (85\%) had no improvement (16). A smaller series that included multiple causes of POVL after spine surgery $(22 / 37$ ION) reported no change in $68 \%$ and worsening in $3 \%$ (23).

\section{RISK FACTORS}

Given lack of effective treatments or spontaneous recovery there is substantial interest in risk stratification (e.g., based on preexisting conditions), and prevention (e.g., through modifying 
surgical or anesthesia practices). This risk stratification is of importance to patients, who prefer to be informed of the risk of visual loss (24). Though there are no prospective studies, case series, case-control studies, and medical claims-based studies have identified candidate risk factors. To date, no risk prediction model or stratification have been reported.

\section{Extrapolation From Spontaneous NAION}

One strategy to identify risk factors is extrapolation from the spontaneous correlate to poION, non-arteritic AION. NAION risk factors include a small optic disk characterized by a small cup-to-disk ratio (C/D), with resulting axonal crowding predisposing to injury. Medical claims-based big data studies have identified association between male sex, white race, and diabetes with end organ involvement and NAION (25).

Medications including amiodarone and phosphodiesterase-5 inhibitors prescribed for pulmonary hypertension and erectile dysfunction are associated with NAION (26). While there are no reports of poION where the drugs were taken within $24 \mathrm{~h}$ of surgery, physicians may want to inquire in high risk patients. There is evolving literature supporting obstructive sleep apnea (OSA) as a risk factor for and untreated OSA as a risk factor for second eye involvement of spontaneous NAION (27). A challenge in such extrapolations is that most concern spontaneous NAION, whereas $>50 \%$ of poION is PION. It remains an unstudied area of research if risk factors for spontaneous and perioperative ION are comparable.

\section{Potential Risk Factors for polON in Spine Surgery}

Multiple clinical studies have attempted to identify pre-existing conditions and intra-operative factors associated with poION in spine surgery (For summary, see Table 1). Case series have been striking for capturing the range of perioperative features. A literature based study described lowest hemoglobin 5.8-14.2 g/dL (mean $9.5 \mathrm{~g} / \mathrm{dL}$ ), intraoperative blood loss 0.8-16 L (mean $3.7 \mathrm{~L}$ ), operative duration $3.5-23 \mathrm{~h}$ (mean $8.7 \mathrm{~h}$ ), and lowest systolic blood pressure (SBP) $48-120 \mathrm{~mm} \mathrm{Hg}$ (mean $77 \mathrm{~mm}$ $\mathrm{Hg}$ ) in 83 cases (16). To address limitations in case series, The American Society of Anesthesia (ASA) POVL Registry systematically collected reports with detailed anesthesia and surgical data (28). The 93 cases ( 83 poION and 10 RAO) had mean lowest hematocrit $26 \%$ and mean blood loss $2.0 \mathrm{~L}$. Most underwent surgery $>6 \mathrm{~h}$, often repeat and multilevel procedures. In $33 \%$, lowest $\mathrm{SBP}$ was $>90 \mathrm{~mm} \mathrm{Hg}$ while in $20 \%$, lowest recorded SBP was $\leq 80 \mathrm{~mm} \mathrm{Hg}$. Blood pressure decrease from pre-operative baseline varied widely [the definition of "baseline blood pressure" in anesthetic practice remains controversial (30)] with the majority (57\%) having SBP or mean arterial blood pressure (MAP) 20-39\% below baseline, and 25\% SBP or MAP $40-49 \%$ below baseline. Deliberate hypotension was used to decrease blood loss in 25\%. Median crystalloid fluid administration was $10 \mathrm{~L}$. Surgical positioning devices included the Wilson frame (30\%) and Jackson spinal table (27\%). Mean age was 50 y. Pre-existing hypertension was in $41 \%$, diabetes $16 \%$, and coronary artery disease $10 \%$. Another series of 37 cases included 8 AION and 14 PION. Less than half had each of hypertension, diabetes, vascular disease, and smoking history. No known vascular risk factors were in 13 (42\%). Comparison of 28 of these cases with matched controls found longer operative time and blood loss, but no difference in age, hematocrit or blood pressure (23).

To address the limitation of lacking a comparison group, the ASA-POVL Group conducted a case-control study using the Registry and randomly selected, matched controls from 17 academic US and Canadian medical centers (18). By multivariable regression, the six factors associated with poION were male sex, obesity, Wilson frame use, anesthesia duration, large blood loss, and low colloid:crystalloid fluid ratio (Table 2). Limitations are that affected cases were not randomly obtained; rather by anonymous case submissions, of which only a small percentage were confirmed by direct examination of anesthesia records, and missing data. Additionally, it could be argued that the controls are not a random sample of patients undergoing spine fusion, as all were derived only from academic medical centers.

The Nationwide Inpatient Sample (NIS), a random sample of discharges of $20 \%$ of US hospitals, offers advantages of larger sample sizes and less selection bias than the ASA-POVL Registry, but is limited by reduced perioperative data. Analysis from 1993 to 2002 identified hypotension, peripheral vascular disease, and anemia as potential poION risk factors (29). A more recent analysis of $>2.5$ million discharges with spinal fusion identified older age, male, obesity, and blood transfusion to be associated with poION. These results are important because they were obtained in a very large, randomly collected sample, and suggest the importance of specific pre-operative factors. However, the conclusions rely upon the accuracy of procedure and diagnosis identification based on International Classification of Disease (ICD9) coding with both over- and under-coding possible (31). Also, the definition, timing of (intraor post-operative), and degree of terms such as hypotension are not specified. Independent confirmation is not possible. A potential application of results from such a population sample is developing risk stratification models applicable to the typical spinal fusion patient.

\section{Potential Risk Factors for polON in Cardiac Surgery}

A single center, prospective, case-control study of 602 patients undergoing cardiopulmonary bypass (CPB) identified 8 (1.2\%) with poION (all AION). CPB time was longer (252 vs. $164 \mathrm{~min}$ ), minimum hematocrit lower (18 vs. $21 \%$ ), $24 \mathrm{~h}$ postoperative weight gain higher (18 vs. $11 \%$ ), and more vasoactive drugs were required in poION cases (17). A single center, retrospective, casecontrol study of 28,000 patients from 1976-1994 included 17 poION cases $(0.06 \%)$. PION and AION were not distinguished. PoION cases had lower minimum post-operative hemoglobin and longer CPB. Other associations included clinically severe vascular disease and transfusion. There were no differences in pre- or post-CPB SBP. C/D $<0.3$ was in 5 (29\%) of poION (10). There was no multivariable model to help interpret interactions between the large number of parameters collected. Holy reported similar results, but included other surgical procedures, complicating interpretation with respect to cardiac 
TABLE 1 | Summary of the studies on spine fusion and ION mentioned in this review.

\begin{tabular}{|c|c|c|c|c|}
\hline References & Type & Study size & ION \# & Findings \\
\hline $\begin{array}{l}\text { Buono and Foroozon } \\
\text { (16) }\end{array}$ & Literature based review & $\begin{array}{l}83 \text { (only ION) } \\
\text { Lumbar spine }\end{array}$ & 83 & $\begin{array}{l}\text { *Mean hemoglobin } 9.5 \mathrm{~g} / \mathrm{dl} \\
\text { *Mean blood loss } 3.7 \mathrm{~L} \\
\text { *Mean operative duration } 8.7 \mathrm{~h} \text { *Mean lowest SBP } 77 \mathrm{~mm} \mathrm{Hg}\end{array}$ \\
\hline Lee (28) & $\begin{array}{l}\text { ASA POVL Registry (anonymous } \\
\text { case submissions) }\end{array}$ & $\begin{array}{l}93 \\
\text { Lumbar spine }\end{array}$ & 83 & $\begin{array}{l}\text { *Lowest mean hematocrit } 26 \% \\
\text { *Mean blood loss } 2.0 \mathrm{~L} \text {. } \\
\text { *Operative duration mostly > } 6 \mathrm{~h} \\
\text { *33\%, lowest SBP was > } 90 \mathrm{~mm} \mathrm{Hg} \\
\text { *20\%, lowest recorded SBP was } \leq 80 \mathrm{~mm} \mathrm{Hg} . \\
\text { *57\% had SBP or MAP 20-39\% below baseline } \\
\text { *25\% SBP or MAP 40-49\% below baseline. } \\
\text { *Deliberate hypotension in } 25 \% \text {. } \\
\text { *Median crystalloid fluid } 10 \mathrm{~L} \text {. } \\
\text { *Surgical positioning: Wilson frame } 30 \% \text { and Jackson spinal table } 27 \% \text {. } \\
\text { *Mean age } 50 .\end{array}$ \\
\hline Myers (23) & Case control single institution & $\begin{array}{l}37 \\
\text { Lumbar spine }\end{array}$ & 22 & $\begin{array}{l}{ }^{*} \text { Age, lowest hematocrit and lowest blood pressure no different in } \\
\text { cases vs. controls } \\
{ }^{*}<50 \% \text { hypertension, diabetes, vascular disease, and smoking history. } \\
{ }^{*} \text { No known vascular risk factors in } 42 \% \text {. }\end{array}$ \\
\hline Lee (18) & Case control multi-institutional & $\begin{array}{l}395 \\
\text { Lumbar spine }\end{array}$ & 80 & See Table 2 for main findings \\
\hline Patil (29) & Case control using NIS & $\begin{array}{l}600,000 \text { lumbar fusion } \\
\text { (also studied cervical } \\
\text { spine) }\end{array}$ & About 120 & $\begin{array}{l}\text { *Incidence about } 0.02 \% \\
{ }^{*} \text { Increased odds ratio for ION with: } \\
\text { Peripheral vascular disease, Diabetes, Hypertension, Obesity, Anemia, } \\
\text { Blood transfusion, Hypotension }\end{array}$ \\
\hline Rubin (7) & Case control using NIS & 2.5M lumbar fusion & 257 & $\begin{array}{l}\text { *Incidence about } 0.01 \% \\
{ }^{*} \text { Increased odds ratio for ION with: age, transfusion, and obesity. } \\
\text { Female sex was protective }\end{array}$ \\
\hline
\end{tabular}

ION, ischemic optic neuropathy; MAP, mean arterial blood pressure; SBP, systolic arterial blood pressure.

surgery (32). All of these studies are limited by small size and single institution design.

A study of $>5$ million cardiac surgery discharges in NIS between 1998 and 2013, found 794 (0.014\%) poION cases. In a multivariable model, poION was associated with male sex, carotid artery stenosis, stroke, diabetic, or hypertensive retinopathy, macular degeneration, glaucoma, and cataract. Cataract was included as a surrogate marker for eye examination to address the concern of under-coding with respect to eye conditions in discharges without poION. Including cataract adjusts model estimates for the confounding variable of eye exam. Therefore, demonstration of positive associations in the models that adjust for cataract increases confidence that other eye diseases are true associations. Intriguingly, this suggests that degenerative eye diseases are associated with poION, raising the possibility of a role of local pre-existing disease in the $\mathrm{ON}$, and the possibility of constructing risk models based on these conditions (6). Limitations are, in addition to those for claims data in general, that type of poION was not identified.

\section{MECHANISM}

\section{Insight From Spontaneous NAION}

There is considerable literature with respect to spontaneously developing NAION. Delayed filling of the prelaminar optic disk in $76 \%$ of NAION eyes and not in normals suggests the
TABLE 2 | Factors increasing the odds ratio of developing perioperative ion in lumbar spine fusion surgery.

\begin{tabular}{lrr}
\hline & Odds Ratio & $\boldsymbol{P}$ Value \\
\hline Male & $2.53(1.35-4.91)$ & 0.005 \\
Obesity & $2.83(1.52-5.39)$ & 0.001 \\
Wilson frame & $4.30(2.13-8.75)$ & $<0.001$ \\
Anesthesia duration, per hour & $1.39(1.22-1.58)$ & $<0.001$ \\
Estimated blood loss, per 1L & $1.34(1.13-1.61)$ & 0.001 \\
Colloid as percent of non-blood replacement, per 5\% & $0.67(0.52-0.82)$ & $<0.001$
\end{tabular}

The risk factors were determined using a multivariable analysis in a case-control study. Details are in reference \#(18).

filling defect is the primary process, not disk edema (33). Early disruption of the blood-brain barrier in AION, with dye leakage in the ON head (34), correlates with early onset of optic disk edema, even before symptoms (35). A generally accepted theory is that an initial insult leads to optic disc edema and secondary injury to neighboring cells.

Hayreh attributed NAION to individual variations in $\mathrm{ON}$ blood supply and watershed areas (36). This theory is supported by anatomic studies and variability of NAION's visual loss. But, inconsistent is that delayed filling of watershed zones was more common in normal eyes than in NAION (34). It has 
therefore been proposed that reduced perfusion pressure in the region of the para-optic branches of the short posterior ciliary arteries (SPCAs, Figure 1) results in optic disk hypoperfusion, rather than a watershed event (37). Histopathologic examination showed that the infarction was mainly retrolaminar, implicating the SPCAs as the cause of the ischemia (38). Studies in healthy humans generally show preserved anterior ON head blood flow within physiological or lower ranges of perfusion pressure, suggesting that impaired autoregulation may play a role (39-41).

\section{Insight From Histologic Examination of Peri-Operative and Spontaneous PION}

Histology has been reported in three PION cases after surgical procedures. All showed infarcts in the intra-orbital ON, two with lesions in the axial center and peripheral axonal sparing. The third had peripheral lesions with central axonal sparing in one eye and complete axonal loss in the other (16). It is possible that the location of ischemia varies between cases due to differences is vascular anatomy (42) but this theory requires further study.

A series of 12 cases of posterior $\mathrm{ON}$ ischemia in an autopsy study of the $\mathrm{ON}$ and chiasm from 53 patients with cerebrovascular disease divided their findings into three stages (43). Pre-morbid visual status was not reported. Acute stage had swollen lesions sharply demarcated from healthy tissue with capillary congestion, swollen axons, and myelin sheaths at the infarct periphery. Intermediate stage showed necrosis, and the chronic stage liquefaction and scar. Similar to poION, location of the ischemic lesions varied with respect to longitudinal and axial location. All had atherosclerotic changes in the intracranial portion of the internal carotid artery and ophthalmic artery, suggesting a role for pre-existing vascular disease.

\section{Insight From Animal Studies}

The role of proposed inciting intra-operative factors has been investigated in targeted studies. It has been shown in miniature pigs that blood flow in the $\mathrm{ON}$ head, as measured by laser Doppler, was maintained during isovolumic hemodilution with hematocrit decreased 30\% (44). In a more extreme model, hematocrit at $15 \%$ and MAP $50 \mathrm{~mm} \mathrm{Hg}$ significantly reduced total ON blood flow in pigs (45). In the absence of hemodilution, blood flow was preserved in various locations of the optic nerve, including the retrolaminar area, at MAP as low as $40 \mathrm{~mm} \mathrm{Hg}$ (46). The effects on $\mathrm{ON}$ function and histology were not reported in either study. Another limitation is that the blood supply to the $\mathrm{ON}$ in pigs differs from humans (47). Taken together, these results demonstrate the robust homeostatic mechanisms for $\mathrm{ON}$ head blood supply and suggest multiple perturbations may be necessary to compromise it.

A model that nearly recapitulates some intraoperative events is hemodilution and extreme head down tilt in rats (8), which altered $\mathrm{ON}$ function with decreased VEPs and decreased electrical activity (scotopic threshold potential) originating in retinal ganglion cells. Although there was increased $\mathrm{ON}$ glial reactivity, frank ischemia was not observed. A rodent model of PION consisting of ischemia induced using photochemical techniques may have application to therapy development, but does not inform understanding of the mechanism of the perioperative form of the disease (48).

\section{TREATMENT}

No effective treatment exists. Increasing ocular perfusion pressure pharmacologically or increasing hemoglobin via transfusion may be appropriate when poION is present with hypotension and/or anemia. Both of these interventions as well as hyperbaric oxygen have been associated with improved vision in case reports (16). Diuretics may reduce edema (49), and corticosteroids may reduce axonal swelling, but risk increased wound infection (50). Neither are used widely and have no proven benefit. The use of neuroprotective agents or drugs that lower intraocular pressure with the goal of increasing blood supply to the $\mathrm{ON}$ are valuable in theory but have never been shown to result in vision improvement.

\section{POTENTIAL STRATEGIES FOR PREVENTION}

Though pre-existing conditions may improve risk stratification, it is operative factors that offer opportunities for direct intervention. The following have received attention due to their theoretical role, and evidence from animal or human studies. None are proven to reduce risk of perioperative ION.

\section{Length of Surgery}

Myers (23) and the ASA-POVL Study Group (18) reported increased risk with lengthy spinal fusion surgery. Increasingly, minimally invasive spine surgery is used (51) which reduces operative time, blood loss, and fluid requirements. Another strategy is staging, which trades off shorter individual procedures against multiple surgeries with associated increased risks of infection, and spinal instability, with studies to date still too small to reach definitive conclusions (52-56).

\section{Avoiding Hypotension}

Intraoperative hypotension was reported in a majority of cases in one case series and one analysis of the NIS $(23,29)$. However, it has not been confirmed as a risk factor by case control studies $(18,23,32)$. Hypotension is a logical theoretical risk factor $(57,58)$ that may contribute by decreasing perfusion pressure in ONs that are predisposed due to anatomic variation or abnormal auto-regulation with inability to adequately compensate. What constitutes dangerous hypotension is difficult to quantitate due to lack of data (59). Deliberate hypotension should be viewed as one strategy to decrease blood loss in spine surgery, and factors such as patient's age, pre-existing atherosclerotic disease, hypertension, and its level of control, the possible disadvantages of deeper levels of hypotension (e.g., MAP < 60) vs. any possible advantages, and that it can only decrease arterial bleeding, are among factors that should be considered in its use.

\section{Minimizing Hemodilution and Blood Loss}

Anemia, blood loss, and transfusion have been identified in various clinical studies as associated factors. In uncontrolled 
hemorrhage without adequate blood volume maintenance, decreased $\mathrm{O}_{2}$ delivery to the ON could result in ION (60). Allowing hemoglobin to decrease, as may be done to conserve blood in the operative setting, may be putting patients at increased risk for poION (61). However, level of hemoglobin and duration of decrease that constitute danger to the $\mathrm{ON}$ is not known. From the animal studies shown above, caution should be exercised with simultaneous deep levels of hypotension and hemodilution.

\section{Head Positioning}

The ASA-POVL case control study showed an association between poION and the Wilson frame use (18). This could be due to venous hypertension. The head may be below the level of the back, in contrast to the Jackson table, where the head is maintained level (62). Positioning effects are evident even in healthy volunteers, who had an increase in ON diameter following prone positioning (63). The patient's head should be in a neutral position during spine surgery, and if a Wilson frame is used, the effect can be achieved with pillows to raise the head, or the bed placed in reverse Trendelenburg (63).

\section{Fluid Administration}

ION cases in the ASA-POVL Registry received on average $9.7 \mathrm{~L}$ crystalloid intraoperatively (18), and increased postoperative weight gain was identified in a case-control study of visual loss after heart surgery (17), suggesting, although not proving, a role of fluid administration. The odds of developing poION were increased as \% colloid of non-blood replacement decreased in spine fusion (18). Fluid resuscitation also contributes to hemodilution. In theory, crystalloid fluids may extravasate from vessels leading to a local compartment syndrome in the $\mathrm{ON}$ with edema and compression damaging axons. Colloids may be associated with less edema in the $\mathrm{ON}$, although such an effect has not yet been demonstrated.

\section{Vasoconstrictors}

Shapira showed an association between prolonged epinephrine infusion or long CPB and poION (17). Lee and Lam presented four ION cases in critically ill patients with significant systemic illness and prolonged vasopressors and inotropic agents to

\section{REFERENCES}

1. Biousse V, Nahab F, Newman NJ. Management of acute retinal ischemia: follow the guidelines! Ophthalmology (2018) doi: 10.1016/j.ophtha.2018.03.054. [Epub ahead of print].

2. Biousse V, Newman NJ. Ischemic optic neuropathies. N Eng J Med. (2015) 372:2428-36. doi: 10.1056/NEJMra1413352

3. De la Garza-Ramos R, Samdani AF, Sponseller PD, Ain MC, Miller NR, Shaffrey CI, et al. Visual loss after corrective surgery for pediatric scoliosis: incidence and risk factors from a nationwide database. Spine J. (2016) 16:51622. doi: 10.1016/j.spinee.2015.12.031

4. Gayat E, Gabison E, Devys JM. Case report: bilateral angle closure glaucoma after general anesthesia. Anesth Analg. (2011) 112:126-8. doi: 10.1213/ANE.0b013e3182009ad6

5. Frenkel RE, Shin DH. Prevention and management of delayed suprachoroidal hemorrhage after filtration surgery. Arch Ophthalmol. (1986) 104:1459-63. maintain blood pressure and cardiac output (64). Based on observation of AION in patients with massive hemorrhage, Hayreh proposed that AION is related to excessive secretion of vasoconstrictors that lowered $\mathrm{ON}$ perfusion to low levels (65). However the mechanism is not clear as $\alpha$-adrenergic receptors are not in the $\mathrm{ON}$ and the blood-brain barrier prevents entry of systemically administered agents, except possibly in the prelaminar zone. Therefore, the role of vasopressor use in poION remains unclear.

\section{CONCLUSION}

Large retrospective studies provided encouraging results that incidence of poION in spinal fusion has significantly declined. Case-control studies have suggested that both pre-operative factors (e.g., pre-existent diseases including pre-existing ophthalmic disease), as well as intraoperative factors such as fluid management, may increase risk of developing perioperative ION in non-ophthalmic surgeries. Although mechanisms of poION in non-ophthalmic surgery remain poorly understood, recent animal studies have provided insight into how proposed contributing factors may act together to cause poION. Diagnostic advances in imaging including diffusion weighted MR may enable early diagnosis.

\section{AUTHOR CONTRIBUTIONS}

All authors listed have made a substantial, direct and intellectual contribution to the work, and approved it for publication.

\section{FUNDING}

National Institutes of Health grants R21 EY027447 (SR), R01 EY10343 (SR), K23 EY 024345 (HEM), P30 EY 026877 to the Department of Ophthalmology at Stanford University, P30 EY 001792 to the Department of Ophthalmology at the University of Illinois at Chicago, unrestricted grants from Research to Prevent Blindness to the Stanford University Department of Ophthalmology and to the University of Illinois at Chicago. 
10. Nuttall GA, Garrity JA, Dearani JA, Abel MD, Schroeder DR, Mullany CJ. Risk factors for ischemic optic neuropathy after cardiopulmonary bypass: a matched case/control study. Anesth Analg. (2001) 93:1410-6. doi: 10.1097/00000539-200112000-00012

11. Kalyani SD, Miller NR, Dong LM, Baumgartner WA, Alejo DE, Gilbert TB. Incidence of and risk factors for perioperative optic neuropathy after cardiac surgery. Ann Thor Surg. (2004) 78:34-7. doi: 10.1016/j.athoracsur.2004.02.015

12. Schobel GA, Schmidbauer M, Millesi W, Undt G. Posterior ischemic optic neuropathy following bilateral radical neck dissection. Int J Oral Maxillofac Surg. (1995) 24:283-7. doi: 10.1016/S0901-5027(95)80030-1

13. Fenton S, Fenton JE, Browne M, Hughes JP, Connor MO, Timon CI. Ischaemic optic neuropathy following bilateral neck dissection. J Laryngol Otol. (2001) 115:158-60. doi: 10.1258/0022215011907613

14. Kaeser PF, Borruat FX. Visual loss after orthopedic procedures. J Arthro. (2011) 26:338.e17-9. doi: 10.1016/j.arth.2009.11.010

15. Huang TW, Liu CM, Cheng PW, Yang CH. Posterior ischemic optic neuropathy following endoscopic sinus surgery. Otolaryngol Head Neck Surg. (2003) 129:448-50. doi: 10.1016/S0194-5998(03)00624-7

16. Buono LM, Foroozan R. Perioperative posterior ischemic optic neuropathy: review of the literature. Surv Ophathalmol. (2005) 50:15-26. doi: 10.1016/j.survophthal.2004.10.005

17. Shapira OM, Kimmel WA, Lindsey PS, Shahian DM. Anterior ischemic optic neuropathy after open heart operations. Ann Thorac Surg. (1996) 61:660-6. doi: 10.1016/0003-4975(95)01108-0

18. Lee LA, Roth S, Todd MM, Posner KL, Polissar NL, Neradilek MB, et al. The postoperative visual loss study group. risk factors associated with ischemic optic neuropathy after spinal fusion surgery. Anesthesiology (2012) 116:15-24. doi: 10.1097/ALN.0b013e31823d012a

19. Vaphiades MS. Optic nerve enhancement in hypotensive ischemic optic neuropathy. J Neuro-Ophthalmol. (2004) 24:235-6. doi: 10.1097/00041327-200409000-00011

20. Bolacchi F, Garaci FG, Martucci A, Meschini A, Fornari M, Marziali S, et al. Differences between proximal versus distal intraorbital optic nerve diffusion tensor magnetic resonance imaging properties in glaucoma patients. Invest Ophthalmol Vis Sci. (2012) 53:4191-6. doi: 10.1167/iovs.11-9345

21. Quddus A, Lawlor M, Siddiqui A, Holmes P, Plant GT. Using diffusionweighted magnetic resonance imaging to confirm a diagnosis of posterior ischaemic optic neuropathy: two case reports and literature review. Neuroophthalmology (2015) 39:161-5. doi: 10.3109/01658107.2015.1021054

22. Parisi V, Gallinaro G, Ziccardi L, Coppola G. Electrophysiological assessment of visual function in patients with non-arteritic ischaemic optic neuropathy. Eur J Neurol. (2008) 15:839-45. doi: 10.1111/j.1468-1331.2008.02200.x

23. Myers MA, Hamilton SR, Bogosian AJ, Smith CH, Wagner TA. Visual loss as a complication of spine surgery. A review of 37 cases. Spine (1997) 22:1325-9. doi: 10.1097/00007632-199706150-00009

24. Corda DM, Dexter F, Pasternak JJ, Trentman TL, Nottmeier EW, Brull SJ. Patients' perspective on full disclosure and informed consent regarding postoperative visual loss associated with spinal surgery in the prone position. Mayo Clin Proc. (2011) 86:865-8. doi: 10.4065/mcp.2011.0279

25. Cestari DM, Gaier ED, Bouzika P, Blachley TS, De Lott LB, Rizzo JF, et al. Demographic, systemic, and ocular factors associated with nonarteritic anterior ischemic optic neuropathy. Ophthalmology (2016) 123:2446-55. doi: 10.1016/j.ophtha.2016.08.017

26. Lee MS, Vaphiades M. Are erectile dysfunction medications causally related to nonarteritic anterior ischemic optic neuropathy? J Neuro-ophthalmology (2016) 36:202-7. doi: 10.1097/WNO.0000000000000342

27. Aptel F, Khayi H, Pépin J, Tamisier R, Levy P, Romanet JP, et al. Association of nonarteritic ischemic optic neuropathy with obstructive sleep apnea syndrome: Consequences for obstructive sleep apnea screening and treatment. JAMA Ophthalmol. (2015) 133:797-804. doi: 10.1001/jamaophthalmol.2015.0893

28. Lee LA, Roth S, Posner KL, Cheney FW, Caplan RA, Newman NJ, et al. The American Society of anesthesiologists postoperative visual loss registry: analysis of 93 spine surgery cases with postoperative visual loss. Anesthesiology (2006) 105:652-9.

29. Patil CG, Lad EM, Lad SP, Ho C, Boakye M. Visual loss after spine surgery: a population-based study. Spine (2008) 33:1491-6. doi: 10.1097/BRS.0b013e318175d1bf
30. Drummond JC, Blake JL, Patel PM, Clopton P, Schulteis G. An observational study of the influence of "white-coat hypertension" on day-of-surgery blood pressure determinations. J Neurosurg Anesthesiol. (2013) 25:154-61. doi: 10.1097/ANA.0b013e31827a0151

31. Golinvaux NS, Bohl DD, Basques BA, Grauer JN. Administrative database concerns: accuracy of international classification of diseases, ninth revision coding is poor for preoperative anemia in patients undergoing spinal fusion. Spine (2014) 39:2019-23. doi: 10.1097/BRS.00000000000 00598

32. Holy SE, Tsai JH, McAllister RK, Smith KH. Perioperative ischemic optic neuropathy: a case control analysis of 126,666 procedures at a single institution. Anesthesiology (2009) 110:246-53. doi: 10.1097/ALN.0b013e318194b238

33. Arnold AC. Pathogenesis of nonarteritic anterior ischemic optic neuropathy. J Neuro-ophthalmol. (2003) 23:157-63

34. Arnold AC, Hepler RS. Flourescein angiography in acute nonarteritic anterior optic neuropathy. Am J Ophthalmol. (1994) 117:222-30.

35. Subramanian PS, Gordon LK, Bonelli L, Arnold AC. Progression of asymptomatic optic disc swelling to non-arteritic anterior ischaemic optic neuropathy. Br J Ophthalmol. (2017) 101:671-5. doi: 10.1136/bjophthalmol-2016-309250

36. Hayreh SS. Blood supply of the optic nerve head: A "reality check." In: Pillunat LE, Harris A, Anderson DR, Greve EL, editors. Current Concepts in Ocular Blood Flow in Glaucoma. (The Hague: Kugler) (1999). p. 3-31.

37. Olver JM, Spalton DJ, McCartney AC. Microvascular study of the retrolaminar optic nerve in man. The possible significance in anterior ischaemic optic neuropathy. Eye (1990) 4:7-24.

38. Knox DL, Kerrison JB, Green WR. Histopathologic studies of ischemic optic neuropathy. Trans Am Ophthalmol Soc. (2000) 98:203-20

39. Pillunat LE, Anderson DR, Knighton RW, Joos KM, Feuer WJ. Autoregulation of human optic nerve head circulation in response to increased intraocular pressure. Exp Eye Res. (1997) 64:737-44. doi: 10.1006/exer.1996.0263

40. Movaffaghy A, Chamot SR, Petrig BL, Riva CE. Blood flow in the human optic nerve head during isometric exercise. Exp Eye Res. (1998) 67:561-8. doi: 10.1006/exer.1998.0556

41. Hayreh SS. Blood flow in the optic nerve head and factors that may influence it. Prog Retin Eye Res. (2001) 20:595-624.

42. Isayama Y, Hiramatsu K, Asakura S, Takahashi T. Posterior ischemic optic neuropathy. I. Blood supply of the optic nerve. Ophthalmologica (1983) 186:197-203.

43. Isayama $\mathrm{Y}$, Takahashi T. Posterior ischemic optic neuropathy. II. Histopathology of the idiopathic form. Ophthalmologica (1983) 187:8-18. doi: 10.1159/000309286

44. Chamot SR, Petrig BL, Pournaras CJ, Riva CE. Effect of isovolumic hemodilution on oxygen delivery to the optic nerve head. Klin Monatsbl Augenheilkd. (2002) 219:292-5. doi: 10.1055/s-200230656

45. Lee LA, Deem S, Glenny RW, Townsend I, Moulding J, An D, et al. Effects of anemia and hypotension on porcine optic nerve blood flow and oxygen delivery. Anesthesiology (2008) 108:864-72. doi: 10.1097/ALN.0b013e31816c8a30

46. Weinstein JM, Duckrow RB, Beard D, Brennan RW. Regional optic nerve blood flow and its autoregulation. Invest Ophthalmol Vis Sci. (1983) 24:155965.

47. Moren H, Gesslein B, Undren P, Andreasson S, Malmsjo M. Endovascular coiling of the ophthalmic artery in pigs to induce retinal ischemia. Invest Ophthalmol Vis Sci. (2011) 52:4880-5. doi: 10.1167/iovs.11-7628

48. Wang Y, Brown DP Jr, Duan Y, Kong W, Watson BD, Goldberg JL. A novel rodent model of posterior ischemic optic neuropathy. JAMA Ophthalmol. (2013) 131:194-204. doi: 10.1001/2013.jamaophthalmol.271

49. Hayreh SS. Anterior ischaemic optic neuropathy. III. Treatment, prophylaxis, and differential diagnosis. Br J Ophthalmol. (1974) 58:981-9.

50. Saxena R, Singh D, Sharma M, James M, Sharma P, Menon V. Steroids versus no steroids in nonarteritic anterior ischemic optic neuropathy: a randomized controlled trial. Ophthalmology (2018) doi: 10.1016/j.ophtha.2018.03.032. [Epub ahead of print].

51. Bae J, Lee SH. Minimally invasive spinal surgery for adult spinal deformity. Neurospine (2018) 15:18-24. doi: 10.14245/ns.1836022.011 
52. Edwards CC, 2nd, Lessing NL, Ford L, Edwards CC. Deep vein thrombosis after complex posterior spine surgery: does staged surgery make a difference? Spine deform. (2018) 6:141-7. doi: 10.1016/j.jspd.2017.08.012

53. Hassanzadeh H, Gjolaj JP, El Dafrawy MH, Jain A, Skolasky RL, Cohen $\mathrm{DB}$, et al. The timing of surgical staging has a significant impact on the complications and functional outcomes of adult spinal deformity surgery. Spine J. (2013) 13:1717-22. doi: 10.1016/j.spinee.2013.03.005

54. Maddox JJ, Pruitt DR, Agel J, Bransford RJ. Unstaged versus staged posterior-only thoracolumbar fusions in deformity: a retrospective comparison of perioperative complications. Spine J. (2014) 14:1159-65. doi: 10.1016/j.spinee.2013.07.485

55. Passias PG, Poorman GW, Jalai CM, Line B, Diebo B, Park P, et al. Outcomes of open staged corrective surgery in the setting of adult spinal deformity. Spine J. (2017) 17:1091-9. doi: 10.1016/j.spinee.2017.03.012

56. Siemionow K, Tyrakowski M, Patel K, Neckrysh S. Comparison of perioperative complications following staged versus one-day anterior and posterior cervical decompression and fusion crossing the cervicothoracic junction. Neurologia i Neurochirurgia Polska (2014) 48:403-9. doi: 10.1016/j.pjnns.2014.10.001

57. Brown RH, Schauble JF, Miller NR. Anemia and hypotension as contributors to perioperative loss of vision. Anesthesiology (1994) 80:222-6. doi: 10.1097/00000542-199401000-00033

58. Katz DM, Trobe JD, Cornblath WT, Kline LB. Ischemic optic neuropathy after lumbar spine surgery. Arch Ophthalmol. (1994) 112:925-31. doi: 10.1001/archopht.1994.01090190073024

59. Arens JF, Connis RT, Domino KB, Lee LA, Miller NR, Mirza SK, et al. Practice Advisory for Perioperative Visual Loss Associated with Spine Surgery: A Report by the American Society of Anesthesiologists Task Force on Perioperative Blindness. Anesthesiology (2006) 104:1319-28.

60. Hayreh SS. Anterior ischemic optic neuropathy. VIII. Clinical features and pathogenesis of post-hemorrhagic amaurosis. Ophthalmology (1987) 94:1488-502.
61. Williams EL, Hart WMJ, Tempelhoff R. Postoperative ischemic optic neuropathy. Anesth Analg. (1995) 80:1018-29.

62. Apfelbaum JL, Roth S, Connis RT, Domino KB, Lee LA, Nickinovich DG, et al. Practice advisory for perioperative visual loss associated with spine surgery: an updated report by the american society of anesthesiologists task force on perioperative visual loss. Anesthesiology (2012) 116:274-85. doi: 10.1097/ALN.0b013e3182 $3 \mathrm{c} 104 \mathrm{~d}$

63. Grant GP, Szirth BC, Bennett HL, Huang SS, Thaker RS, Heary RF, et al. Effects of prone and reverse trendelenburg positioning on ocular parameters. Anesthesiology (2010) 112:57-65. doi: 10.1097/ALN.0b013e318 $1 \mathrm{c} 294 \mathrm{e} 1$

64. Lee LA, Lam AM. Unilateral blindness after prone lumbar surgery. Anesthesiology (2001) 95:793-5.

65. Hayreh SS, Joos KM, Podhajsky PA, Long CR. Systemic diseases associated with nonarteritic anterior ischemic optic neuropathy. Am J Ophthalmol. (1994) 118:766-80. doi: 10.1016/S0002-9394(14)7 2557-7

Conflict of Interest Statement: SR has provided expert witness evaluation or testimony in cases of POVL on behalf of hospitals, patients, and physicians.

The remaining author declares that the research was conducted in the absence of any commercial or financial relationships that could be construed as a potential conflict of interest.

Copyright $(02018$ Roth and Moss. This is an open-access article distributed under the terms of the Creative Commons Attribution License (CC BY). The use, distribution or reproduction in other forums is permitted, provided the original author $(s)$ and the copyright owner(s) are credited and that the original publication in this journal is cited, in accordance with accepted academic practice. No use, distribution or reproduction is permitted which does not comply with these terms. 